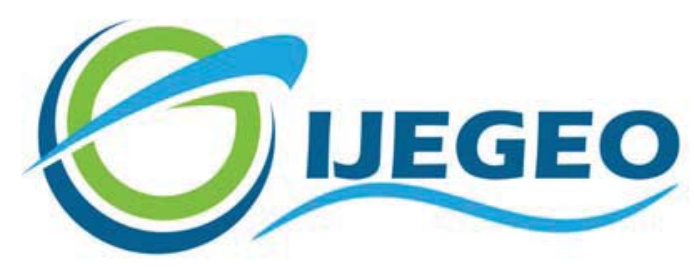

International Journal of Environment and Geoinformatics (IJEGEO) is an international, multidisciplinary, peer reviewed, open access journal.

\title{
Extraction of Roof Planes from Different Point Clouds Using RANSAC Algorithm
}

\section{Fulya GONULTAS, Muhammed Enes ATIK, Zaide DURAN}

\author{
Chief in Editor
}

Prof. Dr. Cem Gazioğlu

Co-Editors

Prof. Dr. Dursun Zafer Şeker, Prof. Dr. Şinasi Kaya,

Prof. Dr. Ayşegül Tanık and Assist. Prof. Dr. Volkan Demir

Editorial Committee (August 2020)

Assos. Prof. Dr. Abdullah Aksu (TR), Assit. Prof. Dr. Uğur Algancı (TR), Prof. Dr. Bedri Alpar (TR), Prof. Dr. Lale Balas (TR), Prof. Dr. Levent Bat (TR), Prof. Dr. Paul Bates (UK), İrşad Bayırhan (TR), Prof. Dr. Bülent Bayram (TR), Prof. Dr. Luis M. Botana (ES), Assos. Prof. Dr. Gürcan Büyüksalih (TR), Prof. Dr. Nuray Çağlar (TR), Prof. Dr. Sukanta Dash (IN), Dr. Soofia T. Elias (UK), Prof. Dr. A. Evren Erginal (TR), Assoc. Prof. Dr. Cüneyt Erenoğlu (TR), Dr. Dieter Fritsch (DE), Prof. Dr. Çiğdem Göksel (TR), Prof.Dr. Lena Halounova (CZ), Prof. Dr. Manik Kalubarme (IN), Dr. Hakan Kaya (TR), Assist. Prof. Dr. Serkan Kükrer (TR), Assoc. Prof. Dr. Maged Marghany (MY), Prof. Dr. Michael Meadows (ZA), Prof. Dr. Nebiye Musaoğlu (TR), Prof. Dr. Masafumi Nakagawa (JP), Prof. Dr. Hasan Özdemir (TR), Prof. Dr. Chryssy Potsiou (GR), Prof. Dr. Erol Sarı (TR), Prof. Dr. Maria Paradiso (IT), Prof. Dr. Petros Patias (GR), Prof. Dr. Elif Sertel (TR), Prof. Dr. Nüket Sivri (TR), Prof. Dr. Füsun Balık Şanlı (TR), Prof. Dr. Uğur Şanlı (TR), Duygu Ülker (TR), Prof. Dr. Seyfettin Taş (TR), Assoc. Prof. Dr. Ömer Suat Taşkın (US), Dr. İnese Varna (LV), Dr. Petra Visser (NL), Prof. Dr. Selma Ünlü (TR), Assoc. Prof. Dr. İ. Noyan Y1lmaz (AU), Prof. Dr. Murat Yakar (TR), Assit. Prof. Dr. Sibel Zeki (TR) 


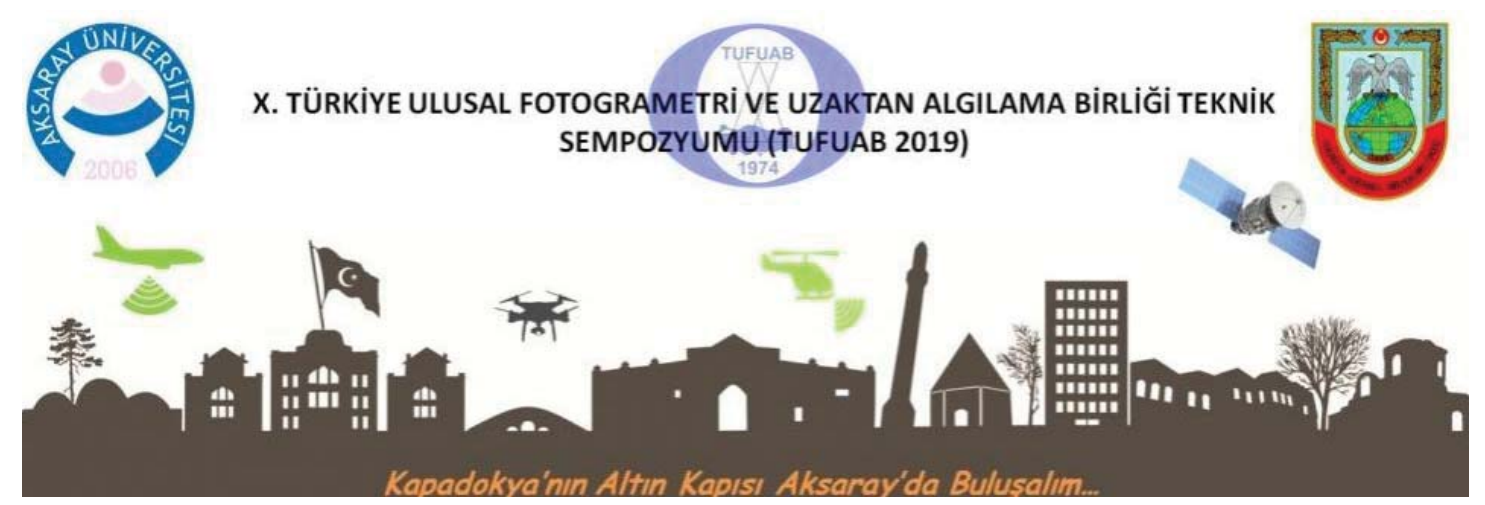

Dear colleagues and friends,

X. TUFUAB Technical Symposium was held in Aksaray on 25-27, April 2019. The Symposium was carried out by the organizations of Aksaray University and General Directorate of Mapping. As a international symposium in the field of photogrammetry and remote sensing, X.TUFUAB Technical Symposium 2019 is devoted to promote the advancement of knowledge, research, development, education and training in Geographical Information Sciences, Information Technology, Environmental Management and Resources, Sustainable Agriculture, Surveying, Photogrammetry and Remote Sensing, their integration and applications, as to contribute to the well-being of humanity and the sustainability of the environment. 425 participants and scientists from 7 countries were attended to this symposium. 125 oral presentations and 10 poster presentations were presented during the symposium. 135 presentations take place in 25 sessions in two days.

The presentations were reviewed by the scientific committee. Nine of these presentations were found worthy to be published in "International Journal of Environment and Geoinformatics (IJEGEO)" by the scientific committee. We would like to thank editorial board of IJEGEO for the publication of these works in the symposium.

Aksaray, Turkey, April 2019.

Prof. Dr. H. Murat YILMAZ

Chair of the Organizing Committee
Dr. Eng. Tuğg. Oman ALP

Director, General Directorate of Mapping 


\title{
Reaserch Article
}

\section{Extraction of Roof Planes from Different Point Clouds Using RANSAC Algorithm}

\author{
Fulya Gonultas, (D) Muhammed Enes Atik*, (iD Zaide Duran \\ Istanbul Technical University, Department of Geomatics Engineering, Istanbul, Turkey \\ * Corresponding author: M. E. Atik \\ E-mail: atikm@itu.edu.tr
}

Received 06 April 2020

Accepted 01 May 2020

How to cite: Gonultas, et al., (2020). Extraction of Roof Planes from Different Point Clouds Using RANSAC Algorithm. International

Journal of Environment and Geoinformatics (IJEGEO), 7(2): 165-171. DOI: 10.30897/ijegeo.715510

\begin{abstract}
Solar energy is a renewable energy source directly from sunlight and its production depends on roof characteristics such as roof type and size. In solar potential analysis, the main purpose is to determine the suitable roofs for the placement of solar panels. Hence, roof plane detection plays a crucial role in solar energy assessment. In this study, a detailed comparison was presented between aerial photogrammetry data and LIDAR data for roof plane recognition applying RANSAC (Random Sample Consensus) algorithm. RANSAC algorithm was performed to 3D-point clouds obtained by both LIDAR (Laser Ranging and Detection) and aerial photogrammetric survey. In this regard, solar energy assessment from the results can be applied. It is shown that, the RANSAC algorithm detects building roofs better on the point cloud data acquired from airborne LIDAR regarding completeness within model, since aerial photogrammetric survey provides noisy data in spite of its high-density data. This noise in the source data leads to deformations in roof plane detection. The study area of the project is the campus of Istanbul Technical University. Accuracy information of the roof extraction of three different buildings are presented in tables.
\end{abstract}

Keywords: Photogrammetry, RANSAC, Point Cloud, Roof Plane, UAV

\section{Introduction}

In the 21 st century, long-term conservation of natural resources, sustainability practices, and environmental monitoring are of great importance throughout the world. Planning of new urban areas in crowded cities is one of the main issues of decision-makers and planners. With developing technology, many advantages emerge for also monitoring urbanization in urban and rural areas. Automated roof detection methods are deployed using effective techniques to detect and monitor buildings in urban areas. Remote sensed data is widely used for fast solutions such as tracking the Earth's surface. Feature extraction techniques are commonly used to observe and analyse specific objects (Atik et al., 2018).

In the recent past, the interest in accurate and detailed 3D building data acquired by airborne LIDAR systems has been growing. Building Information Modelling (BIM), snow load capacity estimating and modelling and solar potential analysis can be given as examples of application areas for building detection (Jochem et al., 2009; Büyüksalih and Gazioğlu, 2019). Today, solar energy can be produced on the rooftops of private houses as easily as in energy companies after detecting proper building roofs.

Building reconstruction is applied by algorithms generally on planar surfaces. However, a fundamental issue that has not been completely solved occurs in building detection. The data from laser scanning measurements taken in the city area mostly includes noise and incompleteness caused by tree points or reflection (Huang et al., 2011; Büyüksalih, 2016; Avşar et al., 2016). There are two different approaches to detect roof planes in literature: Model-driven and data-driven. In the model-driven approach, the algorithms try to find the most suitable model and bring the model as an output from model library computing parameter values. The other approach, namely data-driven, visualizes the building point cloud one by one and then brings the best fitting part as output (Tarsha-Kurdi et al., 2008; Büyüksalih et al., 2018).

In this contribution, a comparison of aerial photogrammetry and LIDAR data in roof plane detection presented with completeness values of each data source. The aim of the study is utilizing RANSAC algorithm on different input sources and assessing these two separate results regarding their accuracy. The main aim of this contribution is evaluating two different data inputs and concluding which data is superior to another in the aspect of accuracy, correctness and completeness.

\section{Materials and Methods}

\section{Study Area}

Study area of the project is located in Istanbul Technical University (ITU)-Ayazaga Campus (Fig. 1). The three buildings that have regular roof planes were selected from both aerial images and LIDAR point clouds to apply the algorithm. Besides single buildings and block buildings, the study area contains small objects such as cars and vegetation types. In the study area, trees that are close to buildings were cleaned up from the buildings to eliminate their influence on roof plane extraction. 


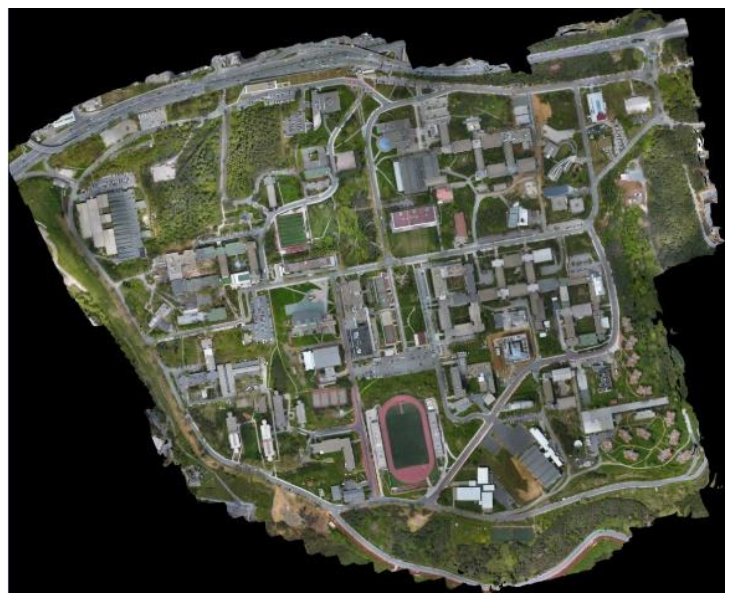

Fig. 1. Orthophoto of ITU-Ayazaga Campus

\section{Data Used}

In the study, two distinct data sources were used: LIDAR data and aerial photogrammetry data.

The airborne LIDAR point cloud was obtained using a laser scanning system. The horizontal and vertical accuracy of the LIDAR data are about $8 \mathrm{~cm}$. Average point density of the data is 16 points $/ \mathrm{m} 2$. Point cloud belonging to three buildings was selected. The selected roofs were shown in Fig. 2, Fig. 3 and Fig.4.

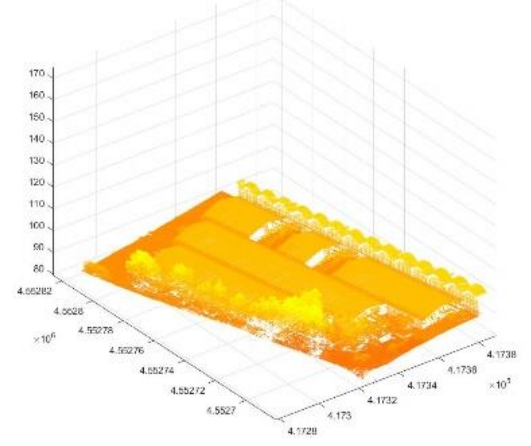

Fig. 2. Aerial LiDAR data of Ari-1 building

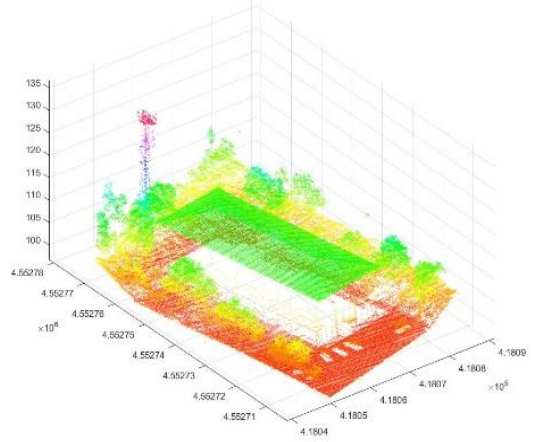

Fig. 3. Aerial LiDAR data of Turk Telekom Building

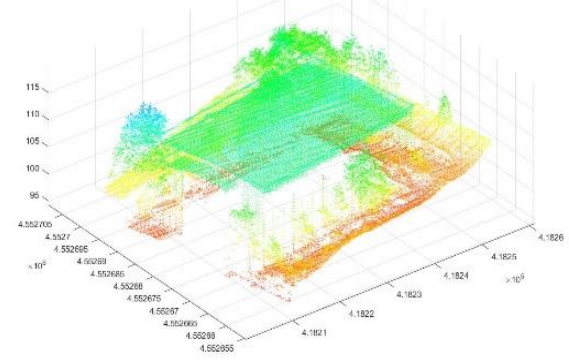

Fig. 4. Aerial LiDAR data of Faculty of Mining

For taking aerial photographs, DJI Phantom 4 Pro was used. The UAV has a sensor with a calibrated focal length of $3.61 \mathrm{~mm}$. Flight parameters were selected as the following: Forward-overlap and side-overlap is $80 \%$ and $70 \%$, respectively. The UAV was flown at a height of $80 \mathrm{~m}$. In total, 288 high resolution images were acquired from the flight. Approximately a Ground Sampling Distance (GSD) of $3.55 \mathrm{~cm} /$ pixel was obtained. It means that one pixel in these images represents $3.55 \mathrm{~cm}$ on the ground. Flight planning was carried out with the help of a software, namely Pix4Dcapture mobile phone application. Aerial photographs of the buildings were represented in Fig. 5, Fig. 6 and Fig 7.

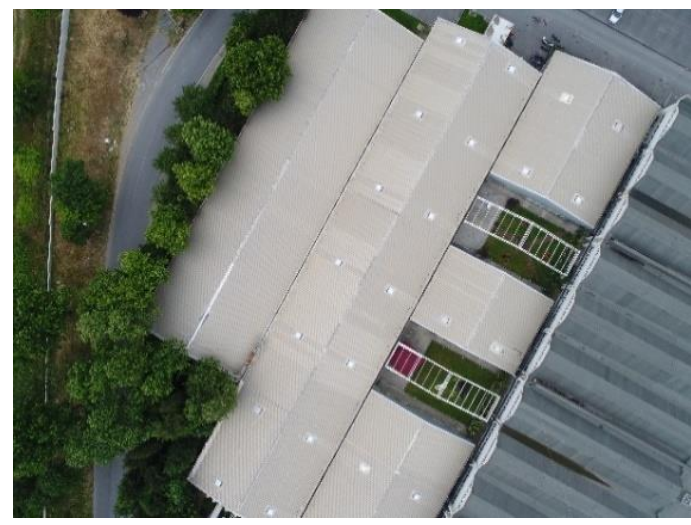

Fig. 5. Aerial photo of Ari-1 building

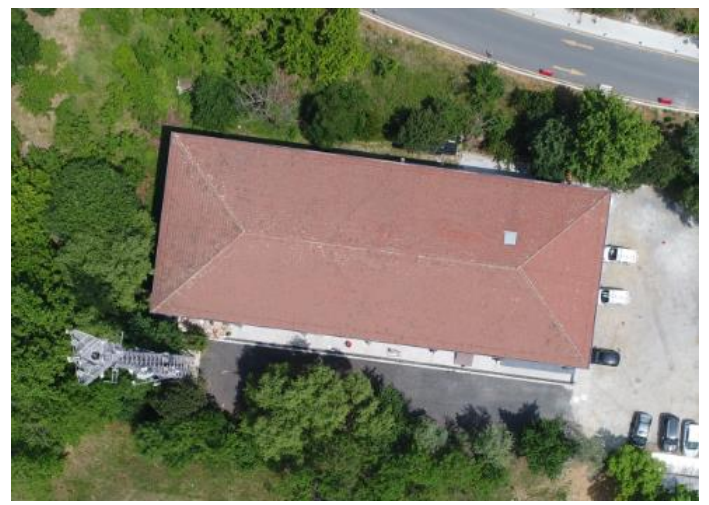

Fig. 6. Aerial photo of Turk Telekom building 


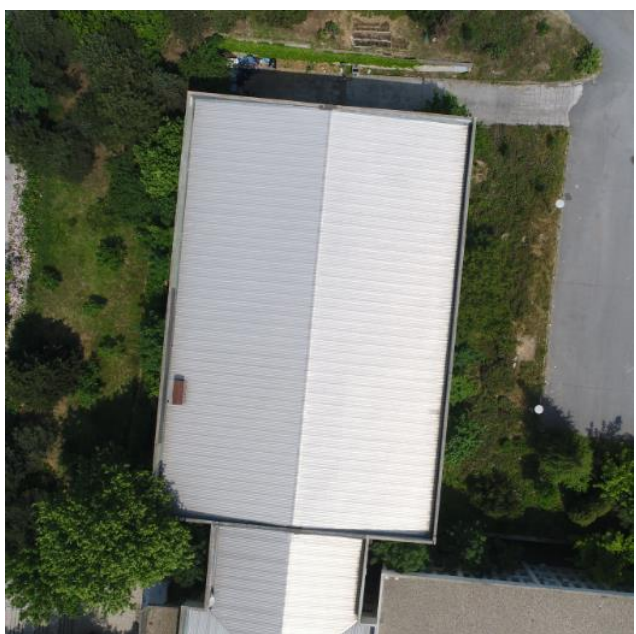

Fig. 7. Aerial photo of Faculty Of Mining

\section{RANSAC}

RANSAC algorithm developed by Fischler and Bolles (1981) is a method to create appropriate solutions of mathematical models in iteration processes. Parameters corresponding to the mathematical model are defined before iteration process. A consensus solution is obtained as the best result (Carrilho and Galo, 2018).

$k=\frac{\log (1-z)}{\log \left(1-w^{n}\right)}$

In the equation $1, \mathrm{n}$ is the minimum number of points which is required for the calculation of the corresponding model. Since minimum 3 points can define a plane, $\mathrm{n}$ is equal to 3 in the case of planar models. Probability $\mathrm{z}$ is a minimum probability value of finding at least one proper set of observations in $\mathrm{N}$ iterations. $\mathrm{z}$ is usually in the range between 0.90 and
0.99. $\mathrm{w}$ is the probability of observations allowed to be incorrect (in percentage).

During the iteration process, algorithm is performed many times and corresponding data set is removed from the original point cloud. The next iteration continues on the remaining points. Finally, iteration is terminated when the number of non-modelled. Points is smaller than defined threshold (Tarsha-Kurdi et al., 2008). An essential advantage of RANSAC algorithm is that number of trials and data size are not directly dependent on each other. Thus, iterations can be quickly obtained on even high-density point clouds (Carrilho and Galo, 2018). Other advantages of RANSAC algorithm are listed below:

- Its concept is simple to apply

- It is a general algorithm and used in a wide variety of applications

- It can robustly work, even if the data includes more than $50 \%$ of outliers (Schnabel et al., 2007).

\section{Experiment}

In order to detect building rooftops, two different sources were used for comparison. LIDAR data is already a point cloud data and RANSAC algorithm is applied on the LIDAR data directly. However, aerial photogrammetry data has to be transformed into 3D point cloud data to apply the proposed algorithm. A software, namely Agisoft Photoscan, was utilized to create a dense point cloud from the aerial images. For the three roof datasets, three different dense point clouds were created using 9, 11 and 20 aerial images, respectively.

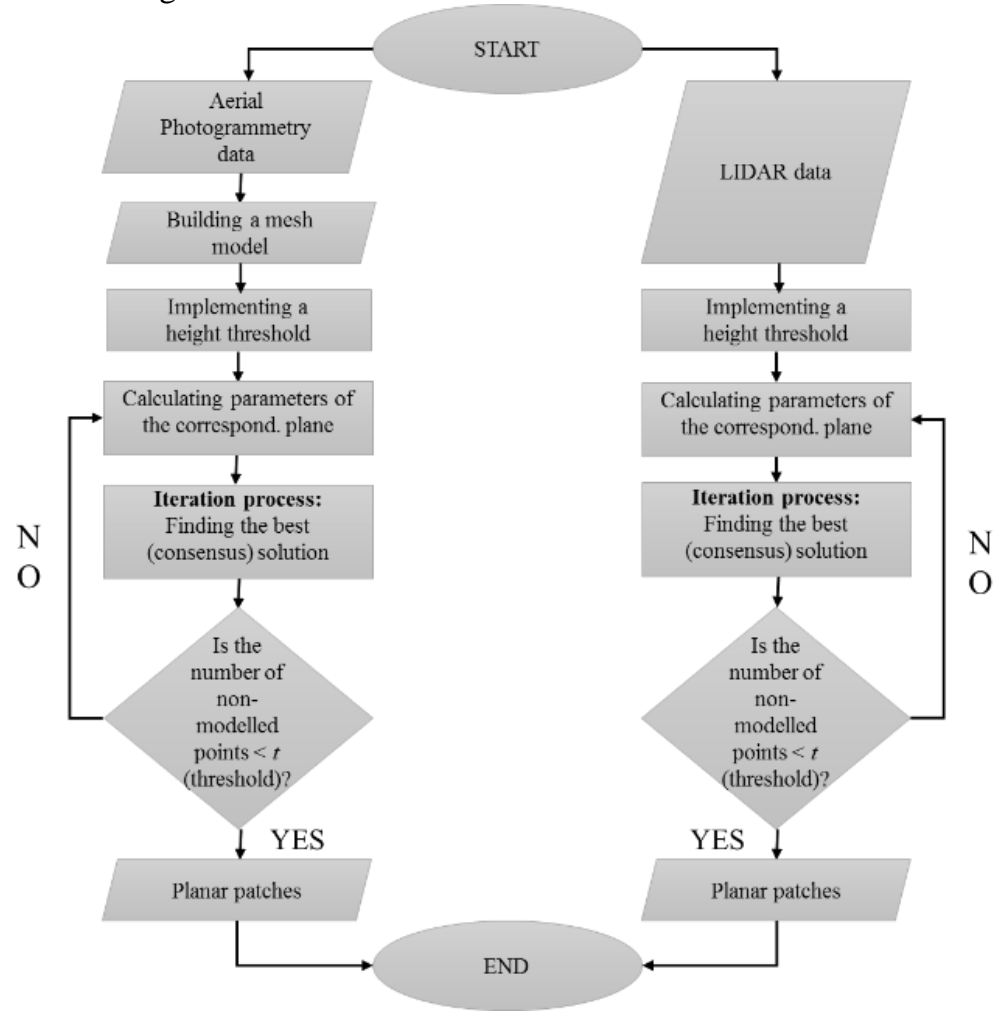

Fig. 8. Flowchart of the proposed roof plane extraction method 
For the selection of roof types, regularity plays an important role as regular roof types can be easily detected with the algorithm. Furthermore, the study focuses on regular rooftop planes only. Therefore, a height threshold was defined for the classification of objects. The points below a predefined height threshold were eliminated from original data to separate ground and non-ground points. Non-ground points included rooftops and high trees. Using all points without any height threshold would result in deformations or incorrect orientation of rooftops. Since each rooftop has different height, threshold value was changed for each building. Threshold values were determined depending on the $\mathrm{Z}$ coordinates of the points and implemented on MATLAB software.

RANSAC algorithm was performed using MATLAB software (Zuliani, M., 2008). During the application of RANSAC algorithm, the largest roof plane in the point cloud data was detected and then this area was removed from the original data. In the next iteration step, the

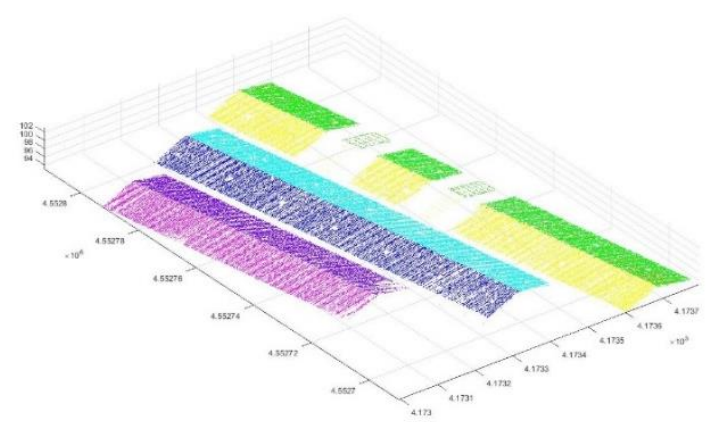

Fig. 9. Detected roof plane from LIDAR data (Ari-1 building)

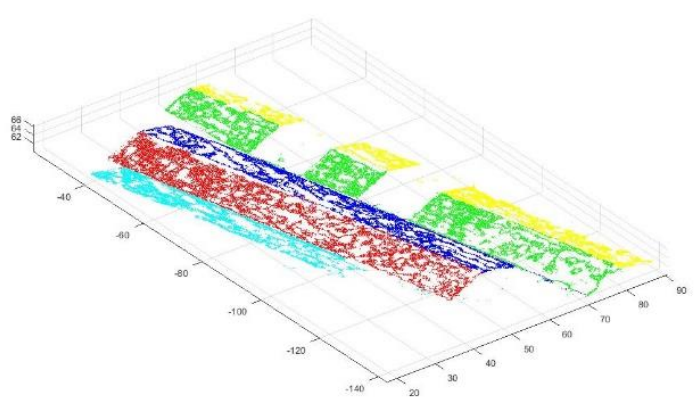

Fig. 10. Detected roof plane from aerial photogrammetry data (Ari-1 building) second largest roof plane can be detected. So, in each step, detected roof plane must be removed in order to find other roof planes. A flowchart of the proposed roof plane extraction method is shown in the Figure 8.

\section{Results and Discussion}

As shown in the following figures, roof planes were extracted separately for LIDAR and aerial photogrammetric data by using RANSAC algorithm. The results from different data sources were compared to each other regarding their error, accuracy, correctness, completeness, by calculating confusion matrix of each plane. The values of reference class were manually calculated on both LIDAR and aerial photogrammetric data. Building roofs consist of multiple surfaces. In the study, these surfaces were extracted separately. Because RANSAC algorithm works as surface extraction one by one. Detected planes were shown in Fig. 9, Fig. 10, Fig. 11, Fig. 12, Fig. 13 and Fig. 14.

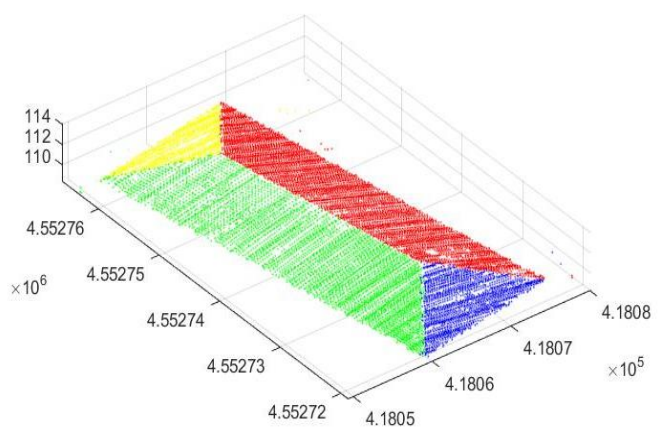

Fig. 11. Detected roof plane from LIDAR data (Turk Telekom building)

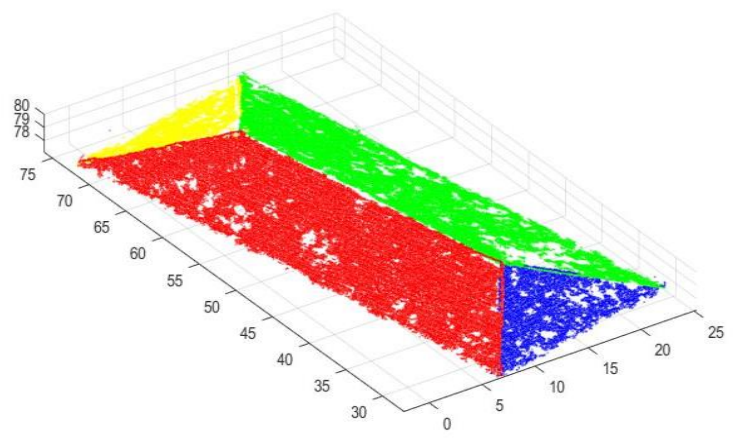

Fig. 12. Detected roof plane from aerial photogrammetry data (Turk Telekom building) 


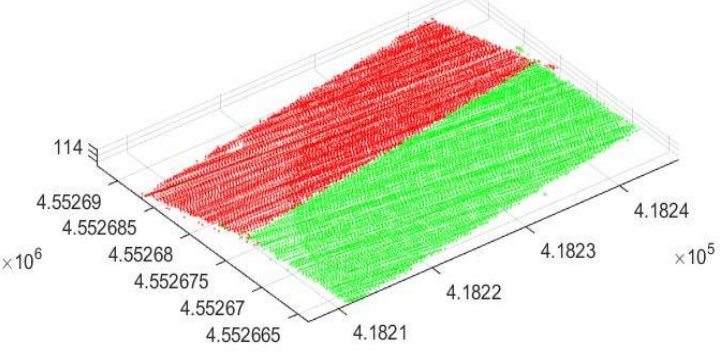

Fig. 13. Detected roof plane from LIDAR data (Faculty of mining)

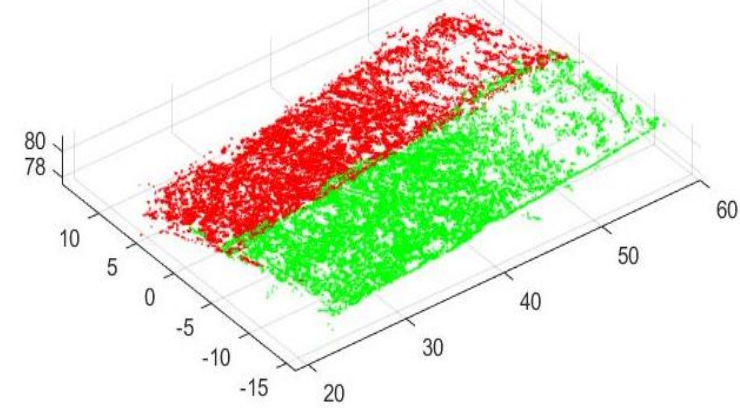

Fig. 14. Detected roof plane from aerial photogrammetry data (Faculty of mining)

Table 1 shows confusion matrix containing True Positive (TP), True Negative (TN), False Positive (FP) and False Negative (FN) values. These values are components of confusion matrix which defines reference class and model class.

Table 1. Confusion matrix (Alpaydin E., 2010).

\begin{tabular}{cccc}
\hline & \multicolumn{2}{c}{ Detected model class } \\
\hline $\begin{array}{c}\text { True class } \\
\text { Reference) }\end{array}$ & Positive & Negative & Total \\
\hline & $\begin{array}{c}\text { True Positive } \\
\text { (TP) }\end{array}$ & $\begin{array}{c}\text { False } \\
\text { Negative } \\
\text { (FN) }\end{array}$ & $\mathrm{p}$ \\
Positive & False Positive & $\begin{array}{c}\text { True } \\
\text { Negative } \\
\text { (FP) }\end{array}$ & $\mathrm{n}$ \\
\cline { 2 - 4 } & p & n' & $\mathrm{N}$ \\
\hline
\end{tabular}

TP: True Positive refers to plane points which are included inside the detected model.

TN: True Negative refers to non-plane points which are outside the detected model.
FP: False Positive refers to plane points which are not included inside the detected model.

FN: False Negative refers to non-plane points which are included inside the detected model.

Error, accuracy, correctness, completeness of the detected plane model can be easily derived from the confusion matrix values. Formulas of the values are mentioned below (Alpaydin, 2010).

Error $=\frac{\mathrm{FP}+\mathrm{FN}}{\mathrm{N}}$

Accuracy $=\frac{\mathrm{TP}+\mathrm{TN}}{\mathrm{N}}=1-$ error

Correctness $=\frac{\mathrm{TP}}{\mathrm{TP}+\mathrm{FP}}$

Completeness $=\frac{\mathrm{TP}}{\mathrm{TP}+\mathrm{FN}}$

The following tables indicate a result of the proposed method. In the results, error means the probability of incorrectly detected points in total. In contrast to error, accuracy refers to the probability of correctly detected points in total. Correctness is the probability of correctly detected plane points. Completeness means how many points that are detected as plane points are plane points in the reality.

Some planes were not detected by using dense point cloud from aerial images. Because there are many tree points on the rooftops and those points cover a part of roof planes. But, on the LIDAR data, all the planes were extracted without any problem. According to the results above, RANSAC algorithm extract more completed model planes on LIDAR data. Because dense point cloud created by aerial photogrammetry produces noisier data. Noisy data can lead to incompleteness in model. But, LIDAR data has more error which means how many points in total are mistakenly detected. The correctness value is greater than 95 percent on all surfaces.

The roof plane detection from the roof surfaces obtained with the LIDAR point cloud has lower accuracy. The reason for this is that the density of the data is lower than the aerial photogrammetry. Only in the Turk Telecom building LIDAR has higher accuracy. However, there is no big difference with air photogrammetry. The percentages of the results were represented in Table 2, Table 3 and Table 4.

Table 2: Analysing of detected roof planes (Ari 1) in regard to their confusion matrix value

\begin{tabular}{|c|c|c|c|c|c|c|c|c|c|c|c|c|}
\hline & \multicolumn{3}{|l|}{ Error } & \multicolumn{3}{|c|}{ Accuracy } & \multicolumn{3}{|c|}{ Correctness } & \multicolumn{3}{|c|}{ Completeness } \\
\hline & $\begin{array}{l}\text { Aerial } \\
\text { data }\end{array}$ & p. & $\begin{array}{l}\text { LIDAR } \\
\text { data }\end{array}$ & $\begin{array}{l}\text { Aerial } \\
\text { data }\end{array}$ & p. & $\begin{array}{l}\text { LIDAR } \\
\text { data }\end{array}$ & $\begin{array}{l}\text { Aerial } \\
\text { data }\end{array}$ & p. & $\begin{array}{l}\text { LIDAR } \\
\text { data }\end{array}$ & $\begin{array}{l}\text { Aerial } \\
\text { data }\end{array}$ & p. & $\begin{array}{l}\text { LIDAR } \\
\text { data }\end{array}$ \\
\hline 1 & $32 \%$ & & $46 \%$ & $68 \%$ & & $54 \%$ & $100 \%$ & & $97 \%$ & $28 \%$ & & $44 \%$ \\
\hline 2 & $30 \%$ & & $47 \%$ & $70 \%$ & & $53 \%$ & $97 \%$ & & $97 \%$ & $28 \%$ & & $44 \%$ \\
\hline 3 & $34 \%$ & & $46 \%$ & $66 \%$ & & $54 \%$ & $98 \%$ & & $98 \%$ & $24 \%$ & & $44 \%$ \\
\hline 4 & $31 \%$ & & $47 \%$ & $69 \%$ & & $53 \%$ & $99 \%$ & & $96 \%$ & $23 \%$ & & $42 \%$ \\
\hline 5 & $20 \%$ & & $55 \%$ & $80 \%$ & & $45 \%$ & $96 \%$ & & $95 \%$ & $28 \%$ & & $33 \%$ \\
\hline 6 & - & & - & - & & - & - & & - & - & & - \\
\hline
\end{tabular}


Table 3. Analyse of detected roof plane (Turk Telekom) in regard to their confusion matrix values.

\begin{tabular}{llllllllll} 
& Error & \multicolumn{3}{c}{ Accuracy } & \multicolumn{2}{l}{ Correctness } & \multicolumn{3}{l}{ Completeness } \\
\cline { 2 - 11 } & $\begin{array}{l}\text { Aerial } \\
\text { p. data }\end{array}$ & $\begin{array}{l}\text { LIDAR } \\
\text { data }\end{array}$ & $\begin{array}{l}\text { Aerial } \\
\text { p. data }\end{array}$ & $\begin{array}{l}\text { LIDAR } \\
\text { data }\end{array}$ & $\begin{array}{l}\text { Aerial } \\
\text { data }\end{array}$ & $\begin{array}{l}\text { LIDAR } \\
\text { data }\end{array}$ & $\begin{array}{l}\text { Aerial } \\
\text { data }\end{array}$ & p. & LIDAR data \\
\hline $\mathbf{1}$ & $41 \%$ & $40 \%$ & $59 \%$ & $60 \%$ & $100 \%$ & $97 \%$ & $48 \%$ & $58 \%$ \\
\hline $\mathbf{2}$ & $64 \%$ & $46 \%$ & $36 \%$ & $54 \%$ & $100 \%$ & $100 \%$ & $35 \%$ & $52 \%$ & $30 \%$ \\
\hline $\mathbf{3}$ & $85 \%$ & $60 \%$ & $15 \%$ & $40 \%$ & $99 \%$ & $99 \%$ & $12 \%$ & $26 \%$ \\
\hline $\mathbf{4}$ & $86 \%$ & $64 \%$ & $14 \%$ & $36 \%$ & $98 \%$ & $96 \%$ & $11 \%$ & \\
\hline
\end{tabular}

Table 4. Analyse of detected roof planes (Faculty of Mines) in regard to their confusion matrix values.

\begin{tabular}{llllllllll}
\hline & Error & \multicolumn{3}{c}{ Accuracy } & \multicolumn{2}{c}{ Correctness } & \multicolumn{2}{c}{ Completeness } \\
\cline { 2 - 10 } & $\begin{array}{l}\text { Aerial } \\
\text { p. data }\end{array}$ & $\begin{array}{l}\text { LIDAR } \\
\text { data }\end{array}$ & $\begin{array}{l}\text { Aerial } \\
\text { p. data }\end{array}$ & $\begin{array}{l}\text { LIDAR } \\
\text { data }\end{array}$ & $\begin{array}{l}\text { Aerial } \\
\text { data }\end{array}$ & $\begin{array}{l}\text { LIDAR } \\
\text { data }\end{array}$ & $\begin{array}{l}\text { Aerial } \\
\text { data }\end{array}$ & p. & LIDAR data \\
\hline $\mathbf{1}$ & $7 \%$ & $16 \%$ & $93 \%$ & $84 \%$ & $96 \%$ & $97 \%$ & $73 \%$ & $85 \%$ \\
\hline $\mathbf{2}$ & $7 \%$ & $19 \%$ & $93 \%$ & $81 \%$ & $96 \%$ & $96 \%$ & $73 \%$ & $82 \%$ \\
\hline
\end{tabular}

Accuracy value which means how many points in total are correctly detected is usually better on dense point cloud data. Also, correctness value which means how many plane points are correctly detected is also better on dense point cloud data, in contrast to LIDAR data.

Non-roof points like ground points should be properly cleaned until there are mostly roof points on the data on which the algorithm is performed. Because the nonroof points can be also detected as plane, if many ground-points exist and they can also define a plane surface.

\section{Conclusion}

In recent years, a lot of algorithms have been developed which detect roof planes. RANSAC algorithm which is one of the most used algorithms on LIDAR data to extract mathematical shapes is represent in this study for a comparison of between aerial photogrammetry and LIDAR data. However, as a main result of this study, data source is very important for successful roof plane detection. In block buildings, algorithm has difficulties to find plane points correctly. It is concluded that irregular shapes of the roofs are not successfully detected. Moreover, tree points or ground points can negatively affect the roof plane detection.

In future studies, larger roof planes can be preferred for better accuracy analysis. For aerial photogrammetry data, more photos should be used. Because, the planes acquired by aerial photogrammetry have many gaps on the rooftop plane. These gaps could be filled with the help of more aerial photographs and completeness value could be increased in this manner.

Reference class can be defined according to other criteria in forthcoming studies. Defining a reference class manually like in this study can cause incorrect classification of points. Considering the results of the study, laser data and optical data can be integrated and used together, since they complement each other.

\section{References}

Alpaydın, E. (2010). Introduction to Machine Learning, Second Edition, The MIT Press.

Atik, M. E., Donmez, S. O., Duran, Z., İpbuker, C. (2018). Comparison of Automatic Feature Extraction Methods for Building Roof Planes By Using Airborne Lidar Data And High Resolution Satellite Image. Proceedings Book of ICCGIS 2018, Bulgaria.

Avşar, E., Bozkurtoğlu, E., Aydar, U., Şeker, DZ., Kaya, Ş., Gazioğlu, C. (2016). Determining Roughness Angle of Limestone Using Optical Laser Scanner. International Journal of Environment and Geoinformatics, 3 (3), 57-75. DOI: $10.30897 /$ ijegeo.306482.

Büyüksalih, G., Baskaraca, P. Bayburt, S., Büyüksalih, İ., Abdul Rahman, A. (2018). 3D City Modelling of Istanbul Based on LIDAR Data and Panoramic Images - Issues and Challenges, The International Archives of the Photogrammetry, Remote Sensing and Spatial Information Sciences, Volume XLII4/W12, 2019 5th International Conference on Geoinformation Science - GeoAdvances 2018, 10 11 October 2018, Casablanca, Morocco.

Büyüksalih, İ. (2016). Building Zone Regulation Compliance Using LIDAR Data: Real-Life Tests in İstanbul. International Journal of Environment and Geoinformatics (IJEGEO), 3(1), 48-55. DOI:10.30897/ijegeo.304428

Büyüksalih, İ., Gazioğlu, C. (2019). New Approach in Integrated Basin Modelling: Melen Airborne LIDAR. International Journal of Environment and Geoinformatics, 6(1), 22-32. DOI: 10.30897/ijegeo.530272

Carrilho, A. C., Galo, M. (2018). Extraction of building roof planes with stratified random sample consensus. The Photogrammetric Record, 33(163), 363-380.

Fischler, M. A., Bolles, R. C. (1981). Random sample consensus: a paradigm for model fitting with applications to image analysis and automated cartography. Communications of the ACM, 24(6), 381-395. 
Huang, H., Li, Z., Gong, P., Cheng, X., Clinton, N., Cao, C., Wang, L. (2011). Automated methods for measuring $\mathrm{DBH}$ and tree heights with a commercial scanning LIDAR. Photogrammetric Engineering \& Remote Sensing, 77(3), 219-227.

Jochem, A., Höfle, B., Rutzinger, M., Pfeifer, N. (2009). Automatic roof plane detection and analysis in airborne lidar point clouds for solar potential assessment. Sensors, 9(7), 5241-5262.

Schnabel, R., Wahl, R., Klein, R. (2007, June). Efficient RANSAC for point- cloud shape detection. In Computer graphics forum (Vol. 26, No. 2, pp. 214-226). Oxford, UK: Blackwell Publishing Ltd.

Tarsha-Kurdi, F., Landes, T., Grussenmeyer, P. (2008). Extended RANSAC algorithm for automatic detection of building roof planes from LiDAR data. The photogrammetric journal of Finland, 21(1), 97109.

Zuliani,M. (2008), RANSAC Toolbox for MATLAB. http://www.mathworks.com/matlabcentral/fileexch ange/18555. 